\title{
A Development and Management Model for "Smart" Temporary Residences
}

\author{
Liala Baiardi, Andrea Ciaramella and Stefano Bellintani
}

\begin{abstract}
The text describes the features of the project for developing and managing smart temporary residences in a circular economy vision, Eco System, Temporary House-ESTH, winner of the Smart Living Tender in the Lombardy region. The research project aims to create a development and management model for "smart" temporary residences by applying a circular economy vision to the construction, furnishing and services industry. The development involves the application to an existing building subject to functional, construction and energy redevelopment through innovative construction and digital technologies. The property's redevelopment is based on a centralised management model for building (property and facility management) and users, thanks to use of the IoT (Internet of things).
\end{abstract}

Keywords Building management $\cdot$ IoT $\cdot$ Process model $\cdot$ Valorisation $\cdot$ Smart living

\section{Introduction}

The ability to organise programmed strategies for the redevelopment of building systems plays a fundamental role within the strategy of enhancing the real estate assets and the urban fabric.

L. Baiardi $(\bowtie) \cdot$ A. Ciaramella $\cdot$ S. Bellintani

Architecture, Built Environment and Construction Engineering-ABC Department, Politecnico di Milano, Milan, Italy

e-mail: liala.baiardi@polimi.it 
$40 \%$ of residential buildings in European Union countries were built before 1960, and almost $84 \%$ are at least 20 years old. For this reason, a large majority of buildings are in a poor state of conservation and unable to meet the basic requirements dictated by user needs and the current legislative framework (European Union-EU 2010).

The need for redevelopment is also strongly motivated by the fact that residential buildings are responsible for a third of the world's final energy consumption (International Energy Agency 2013). It is, thus, essential to rethink energy adjustment to take a major step towards the achievement of environmental objectives in the medium and long term, and therefore create sustainable urban renovations. This requires vigorous policies, as well as effective and conscious actions to reduce the costs associated with the construction industry, in terms of operational and incorporated energy use and related emissions. The International Energy Agency (IEA) aims to achieve an $80 \%$ reduction in global emissions by 2050, which thing led European countries to focus their efforts on the optimisation of energy performance (Passer et al. 2016).

In this respect, the European Commission (EC) has identified the life-cycle assessment (LCA) as the most suitable methodology that is currently available to evaluate the potential environmental impacts and the performance of construction products and buildings (Kylili and Fokaides 2017).

The products have a life cycle that can be defined according to two different approaches: technical and economic. Generally, products with low-quality and economic value are scrapped at the end of their life cycle. For those defined as durable, the possibility is envisaged of carrying out repairs (which do not exceed the value of the product) before finally terminating the life cycle. Finally, for high-value and technically complex products (which make reproduction difficult), maintenance and functional adjustment activities can be initiated that are such as to restart a new life cycle.

The latter is the typical case of real estate products that, generally with a high economic value and low reproducibility, become the object of redevelopment or enhancement. This process consists in the intervention on the building that has become obsolete in order to restart a new technological and economic life cycle for it.

The requirement for a design praxis enhances the significance to the governance of both creative and constructive process, placing the question of method in a multidisciplinary and multi-objective dimension aimed at responding to the rapid change in the quality demand underlying the project itself.

It outlines a file rouge within the cultural debate of the area, making the topic of "method" a key issue of the disciplinary approach.

Indeed, it explains the systemic and complex vision of the design thinking; the procedural nature of operations; the hierarchical structure of the information/decision ratio in project organisation; the capacity of mediating constraints deriving by both the built environment; the biological cycles and the will of responding to the most advanced aspirations of society (Lucarelli and Rigillo 2018). 
The activities of buildings valorisation, compared to traditional restructuring activities, represent an innovative approach with particular attention to processing potential of the property well and putting it in relation to the urban context and the target market needs.

Its fundamental goal is to increase in profitability through the design and construction of a "new and precise identity" of the property.

Starting from the analysis of the characteristics and transformative potential of the building (both from the urbanistic, architectural, layout, plant engineering point of view), we must define the potential need to change the destination in order to obtain the maximum efficiency of performance and profitability.

In particular, the organisation of a process of property enhancement aims to successfully identify and subsequently determine the proportion of unexpressed real estate value, i.e. what can be identified only by fully grasping the characteristics and the potential of the specific asset in relation to market demand in that particular context (Manfredi and Tronconi 2012).

Through a well-structured analysis and design activity it is, thus, possible to identify the opportunity that can best satisfy the cost/performance ratio with respect to the entire life cycle of the building.

Based on this, the text explains the underlying principles of the Eco System Temporary House (ESTH) Works Experimentation and Innovation project funded by the Lombardy region within its Smart Living program. Starting from the desire to enhance an existing building, the project aims to create a management development model for real estate assets.

This approach refers to the actual debate on the relevance of the building balance to the global sustainability, as described by environmental, social, economic and political aspects, that is linked to the restoration of existing buildings.

\section{The Eco System Temporary House (ESTH) Project}

Eco System Temporary House (ESTH) represents an innovative company for the development and management of smart temporary residences through the functional, constructive, energy and seismic redevelopment of existing buildings with innovative construction and digital technologies as well as recycled and recyclable materials in a circular economy vision.

Reconnecting to the principles of resilience management (Walker et al. 2006), the project implements design practices aimed at developing innovation of both product and process, according to the new "eco" paradigm coming from scientific debate (also including those of the ecological engineering and eco-technologies). 
The renovation project involves structural consolidation by means of the technique of static strengthening and also the improvement of energy performance. ${ }^{1}$

Simultaneously are taken into consideration issues such as reducing carbon dioxide emissions, water conservation, rainwater and wastewater management and reuse.

Important aspects for the owner and the handler, not only for the environmental benefits and comfort that follow each other but also for the reduction of energy consumption and cost savings it brings.

The project includes the elaboration of a centralised management model for building (property and facility management) and users (services to the person) thanks to use of the IoT (Internet of things).

The IoT has the potential to allow communication between real and virtual devices in daily life using the Internet. It also focuses on providing information on changes to the state of things in real time. It can be compared to the nervous system in terms of the exchange of information, because the connection between the sensors and actuators that communicate networking suggests the development of intelligent environments (Isikdag 2015).

The IoT, together with detector devices, allows us to extract the "big data" (data and information) directly from the user-building system and reuse it for "continuously improving" the building-eco-system and the performance of services (monitoring the service-level agreement-SLA).

The residences will be allocated to particular categories of users who need to rent a house for a short to medium period, such as workers ("visiting professors" and researchers, entrepreneurs and corporate reality managers), people who need to stay for medical treatment or to care for sick relatives and tourists.

On the basis of a research carried out by Mckinsey on temporary residences, there is a growth in demand for spaces with smart features on the part of freelancers but also companies, small entrepreneurs or innovative start-ups (McKinsey Global Institute 2011).

Places, which have characteristics sometimes halfway between a home and an office, with work spaces and gathering spaces in which you can access, thanks to flexible subscriptions that allow you to occupy single locations, but also offices with

\footnotetext{
${ }^{1}$ The structural redevelopment requires seismic screening solutions by:

- seismic investigation,

- seismic redevelopment intervention aimed at the seismic certification according to the DDL 2017 budget law (in accordance with the "Guidelines for the classification of seismic construction risk"),

- structural and vibrational monitoring for the assessment of safety conditions in the course of the executive and post-intervention phases.
}

Environmental redevelopment requires energy screening such as:

- thermal investigation of shell dispersions and thermal bridges,

- adaptation of the Nzeb Nearly Zero energy building with integrated intervention at building level, plant engineering and low power consumption choice in respect of Leadership in Energy and Environmental Design (LEED) and Lombardy region directives (DGRX 3868). 
multiple desks, meeting rooms and conference rooms for the time you need: a day, a month or more.

This temporary form of use began in America at the beginning of the century and then spread to the major cities of the world.

An example is the American case of WeLive, a widening product of the We Work philosophy based on community and flexibility where the users of the residences have access to the leisure and co-working areas and a wide range of additional services.

In Italy today, the answer to such residential needs in the free market offer shows some weaknesses of both a regulatory and contractual nature and a building nature, i.e. with types unsuited to the housing needs of the reference target.

In line and by way of implementation of the provisions in the PON GOVERNANCE and PON SMART CITY European Directives, Regional Law No. 31 of $28 / 11 / 2014$, which predict a $25-30 \%$ reduction in land use by 2020 , the project is designed to recover existing buildings with zero land consumption.

The concept is based on Corporate social responsibility that is guided towards a circular economy model of the construction and services sector, involving the PEOPLE-PLANET-PROFIT and ECONOMICS OF HAPPINESS sustainable principles through the humanisation of the elements of technological innovation.

\section{The Operational Model}

Planning E.S.T.H. ITALY intends to meet the needs of the hospitality market for serviced apartments as an alternative to traditional hotel rooms.

These kinds of accommodation generally consist in small furnished apartments available for short- or long-term-stays that provide, in addition to cleaning, a range of services for guests and include the price of taxes and utilities.

The "serviced" apartments offer services very similar to those of a traditional hotel, but with more space, comfort and privacy by replicating a more homely environment.

They have a private kitchenette, larger living/sleeping areas than most standard rooms, and often have access to gyms, restaurants, meeting rooms and other services depending on the "residence" target.

For the preparation and experimentation of the model, an abandoned property was chosen in the municipality of Milan whose redevelopment and enhancement are envisaged without demolishing the main structure and with the use of materials and components that can be easily removed, disassembled and reused.

The model contemplates a protocol that has the following as strategic and consequential points:

- the technical-economic due diligence for functional building repurposing;

- the development of the project with BIM aid, the recovery of the building with the functional adaptation of the internal layout to the new housing needs;

- centralised and advanced management with the introduction of value-added services for users. 
The approach is systemic and sees all the envisaged elements as necessarily and systematically interdependent.

The technical-administrative due diligence (planning and construction) includes the investigation of structural and energy diagnostics, thermal bridges and 3D BIM output modelling.

In order to reconfigure and make real estate products on the market attractive, it is necessary to develop the project to match the expectations of potential demand as much as possible.

For this reason, it is necessary to carry out a suitable analysis of the competitive supply and demand in the reference sector.

A functional benchmarking analysis was thus conducted in support of the identification of best business practices applicable to the Eco system Temporary House model.

The underlying philosophy of the Benchmarking process consists of four elements/work phases:

- Knowing one's activities;

- Knowing the business leaders or competitors;

- Incorporating the best;

- Achieving excellence in managing one's activities (Ciaramella and Bellintani 2008).

The identification of the objectives/performance principles the building must attain provides important information for the definition of the project, and as a result, for the building-installation sub systems to be intervened on.

The building is designed as a highly technological eco-system designed in an integrated manner in its architectural, structural and installation parts, thanks to the use of Building Information Modelling software (BIM).

A BIM model not only represents the geometry of the project, but it contains within it all the technical, scientific, commercial and economic information that allows us to have a complete virtual representation of the work planned as the final result, with all the benefits arising from it.

The use of BIM also contributes to the creation of a database capable of containing technical and economic information.

This form of archiving makes it possible to correlate the considerable amount of information necessary in order to maintain an active management of the real estate assets. This information can provide further support in forecasting and monitoring of maintenance activities.

Building information management is the basis of the standards and requirements applied to the data aimed at the use of BIM. The continuity of data allows an effective exchange of information in a context in which sender and receiver understand the information (Va BIM Guide 2010).

The mitigation of the impact on the territory in terms of lower emissions is pursued by applying a "circular" system to the building sector system translated into energy and structural redevelopment interventions, choice of materials and products designed to be circular. 
In this phase, the choices regarding the use of new materials and new construction technologies (e.g. carbon fibres and graphene) are made to facilitate the implementation of "light" structural interventions such as making the structure earthquake-proof and energy efficient.

As implementation of the BIM proceeds in the various phases of the project's life cycle, even the connected models evolve, with a constant enrichment of information. This progressive set of models is sometimes defined using different naming conventions. A common convention in the sector ranks the models as follows:

- the concept stage model (also called the mass model);

- the design stage model (also called the design model - in the case of a construction project we can also talk about an architectural model, a structural model, a MEP model, etc.);

- the construction stage model (also defined as the construction model);

- the operation and maintenance stage model (also defined as the final model).

The application of a centralised management model for building (property and facility management) and users (personal services) is implemented via the use of the IoT (Internet of things).

The IoT, together with detector devices, allows us to extract the "big data" (data and information) directly from the user-building system and reuse it for "continuously improving" the building-eco-system and the performance of services (monitoring the service-level agreement).

Use of the IoT combined with building automation technologies, attention to customer experience (through the use of a dedicated app for iOS and Android smart phones) enable us to meet consumer needs more effectively and manage the environments more efficiently.

The management model involves configuring a property management system (PMS) and the control room.

Property management system is a software programme used to manage room planning, check-in and check-out activities, accounts, and invoicing by accommodation facilities.

The control room represents a "reference model" that can also be used from remote, able to communicate with the BIM and conduct a census (in an interactive and structured manner) on technical/energy, building registry, accounting and tax data, as well as data on maintenance works and guarantees, with the ability to monitor on a remote basis (for example, by means of sensors and Webcams) and return information about individual devices at different levels of detail.

Through the application of the property management system and the interaction with the control room in the building, it is possible to plan and control the location of the units, handle the volumes of incoming and outgoing data, create links to internal and external systems such as hall and utilities systems, and generate reports capable of providing support to the operational and revenue management choices. 


\section{Innovative Aspects and Possible Developments}

Innovation, which starts from the management model for the property (property and facility) and the services to the person, obliges us to rethink the entire construction process from design to implementation and monitoring: the approach of the initiative is systemic and sees all the envisaged elements as necessarily and systematically interdependent.

Thanks to a centralised governance of the data (platform-software-app) and an intelligent management of information, it is possible to extract the big data from both processes, through the use of sensors and control units that represent cognitive systems properly so-called (internal acoustic control, use of home automation and building automation systems), and users, translating them into a holistic view, achieving a continuous improvement of operational processes (service-level agreement-SLA), improving performance and thus ensuring user satisfaction, in addition to ensuring continuity of the $24 \mathrm{~h}$ service.

\section{Conclusions}

The project, in its final phase, leads constructing and testing a model that can be reproduced to meet the demands of a growing market, thereby contributing to the socio-economic development of the community.

The combined use of BIM and IoT technologies plays an important role for increasing the efficiency in customer services and facility management. For this reason, our future efforts will continue in this direction and will focus on investigating the feasibility of this integration with different approaches in building management.

In this research, real-time data from the sensors can be provided and tracked from the web browser. Analysis and visualization of the data from the sensors will be important for manage the building, particularly in view of comfort analysis.

Based on the research work and on the case study illustrated, we can conclude that applying an opportune centralised management model, real estate strategy must prove able to support the building reuse and relocation.

The choice of a correct and adequate definition of spaces and the provision of services to the enterprise and to the organisation is true strategic decisions that can influence the success of a project.

The case study highlights the tight relationship among the, real estate needs, and the material contribution given by the right strategy implemented by the FM or the Real Estate Management departments.

Managers have the responsibility to govern the whole process through its individual stages, involving the participating subjects and allocating the necessary resources. Facility managers are asked to monitor the correct development of the process and, if necessary, to intervene promptly. 
The main indicator of their efficiency is the successful achievement of the set targets within the set deadlines and costs.

Acknowledgements The Eco System Temporary House (ESTH) is funded by the Lombardy region within the context of support to the integrated high-tech building supply chain: manufacturing, services and technology "Lombardy 5.0: policies for the consolidation and enhancement of lombardy's excellent supply chains" known as smart living.

PG Seven S.R.L., Guffanti Group \& partners S.R.L., Universal Selecta S.p.A are partners in the project.

Members of the working group from the Politecnico di Milano: Andrea Ciaramella, Liala Baiardi, Stefano Bellintani, Marzia Morena, Angela Pavesi and Valentina Puglisi.

\section{References}

Ciaramella, A., \& Bellintani, S. (2008). "L'audit immobiliare", Ed Il sole 24 Ore, Milan 2008.

European Union. (2010). European Union (UE) Directive 2010/31/EU of the European Parliament and of the Council of 19 May 2010 on the energy performance of buildings (recast). Official Journal of the European Union, 13-35. https://doi.org/10.3000/17252555.L_2010.153.eng.

International Energy Agency. (2013). World energy Outlook, OECD/IEA, Paris. Retrieved from https://www.iea.org/publications/freepublications/publication/WEO2013.pdf.

Isikdag, U. (2015). BIM and IoT: A synopsis from GIS perspective. In Joint International Geoinformation Conference, 10 (pp. 33-38). Kuala Lumpur: International Archives of the Photogrammetry.

Kylili, A., \& Fokaides, P. A. (2017). Policy trends for the sustainability assessment of construction materials: A review. Sustainable Cities and Society, 35, 280-288. Retrieved from https://www. sciencedirect.com/science/article/pii/S2210670717303773?via\%3Dihub.

Lucarelli, M. T., \& Rigillo, M. (2018). Resilience and technological culture of design: The centrality of method. Techne, Journal of Technology for Architecture and Environment, 15/2018. Italy, 60/64.

Manfredi, L., \& Tronconi, O. (2012). La valorizzazione immobiliare, Maggioli editore, Sant'Arcangelo di Romagna.

McKinsey Global Institute. (2011). Urban world: Mapping the economic power of cities. Retrieved from https://www.mckinsey.com/featuredinsights/urbanization/urban-world-mappingthe-economic-power-of-cities.

Passer, A., Ouellet-Plamondon, C., Kenneally, P., John, V., \& Habert, G. (2016). The impact of future scenarios on building refurbishment strategies towards plus energy buildings. Energy and Building, 124, 153-163. Retrieved from https://www.sciencedirect.com/science/article/pii/ S0378778816302432?via\%3Dihub.

Regional Law dated 28th November 2011, no. 31, provisions for reducing the use of space and for rehabilitating degraded land, (BURL n. 49, suppl. del 01 Dicembre 2014). Retrieved from http://normelombardia.consiglio.regione.lombardia.it/NormeLombardia/Accessibile/main. aspx?iddoc $=1 \mathrm{r} 002014112800031 \&$ view $=$ showdoc.

US Department of Veteran Affairs. (2010). The VA BIM guide, US Department of Veteran Affairs, Washington DC. Retrieved from www.cfm.va.gov/til/bim/BIMGuide/terms.htm.

Walker, B., Gunderson, L., Kinzig, A., Folke, C., Carpenter, S., \& Schultz, L. (2006). A handful of heuristics and some propositions for understanding resilience in social-ecological systems. Ecology and Society, 11(13). 
Open Access This chapter is licensed under the terms of the Creative Commons Attribution 4.0 International License (http://creativecommons.org/licenses/by/4.0/), which permits use, sharing, adaptation, distribution and reproduction in any medium or format, as long as you give appropriate credit to the original author(s) and the source, provide a link to the Creative Commons license and indicate if changes were made.

The images or other third party material in this chapter are included in the chapter's Creative Commons license, unless indicated otherwise in a credit line to the material. If material is not included in the chapter's Creative Commons license and your intended use is not permitted by statutory regulation or exceeds the permitted use, you will need to obtain permission directly from the copyright holder.

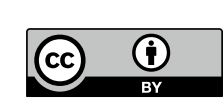

